\title{
An unusual complication of posterior packing in epistaxis
}

\author{
Mehmet Ozgur Erdogan, ${ }^{1}$ Engin Ozturk, ${ }^{2}$ Baris Erdogan, ${ }^{3}$ Mustafa Ahmet Afacan, ${ }^{1}$ Ismail Tayfur, ${ }^{1}$ \\ Kaan Yusufoglu, ${ }^{4}$ Sahin Colak, ${ }^{1}$ Abdullah Algin ${ }^{5}$ \\ ${ }^{1}$ Department of Emergency Medicine, University of Health Sciences Haydarpasa Numune Training and Research Hospital, Istanbul, Turkey \\ 2Department of Emergency Medicine, Aydin Ataturk State Hospital, Aydin, Turkey \\ ${ }^{3}$ Department of Otolaryngology, Medipol University Esenler Training and Research Hospital, Istanbul, Turkey \\ ${ }^{4}$ Department of Emergency Medicine, University of Health Sciences Sisli Etfal Training and Research Hospital, Istanbul, Turkey \\ ${ }^{5}$ Department of Emergency Medicine, Adıyaman University Training and Research Hospital, Adıyaman, Turkey
}

\begin{abstract}
Endonasal or transnasal procedures are sometimes necessary in patients with head trauma. Before these procedures, the integrity of the skull base must be considered to avoid penetration of the cranial vault. A 54-year-old man was taken to a district hospital following a car accident. After the initial assessment and emergency treatment, he was transferred to our emergency clinic for further examination. The patient had massive nasal bleeding, though a Foley catheter had been inserted to control posterior bleeding. Computed tomography (CT) revealed that the catheter was not positioned correctly and was in the cranial vault. Several fractures of the maxillofacial and cranial bones and cervical vertebrae were detected on CT. He also had right hemothorax and bilateral brain contusions. Endonasal insertion of catheters or tubes in trauma patients without a complete assessment of the skull base can cause serious complications.
\end{abstract}

Keywords: Cathater; complication; epistaxis; trauma.

Cite this article as: Erdogan M. O., Ozturk E., Erdogan B., Afacan M. A., Tayfur I., Yusufoglu K., Colak S., Algin A. An unusual complication of posterior packing in epistaxis. North Clin Istanb 2018;5(2):157-159.

Tn patients with head trauma, nasal bleeding can someLtimes be massive and can lead to increased morbidity and mortality [1]. Endonasal or transnasal procedures might be necessary to stop bleeding $[2,3]$. However, before performing these procedures, the integrity of the skull base must be assessed to avoid penetration of the cranial vault. The application of a nasogastric tube, nasal intubation, or posterior packing for severe nasal bleeding can cause penetration of the skull base and severe or even deadly injuries [1].

After the resuscitative measures are undertaken, stopping a major bleeding becomes the first aspect to look into in a trauma patient. Yet, before making an in- tervention, the physician must be sure of the condition of the skull base [1].

In this case report, we present a complication that occurred as a result of inadequate assessment of the skull base before intervention. A detailed discussion of the complication and treatment options is provided with it.

\section{CASE REPORT}

A 54-year-old man with multiple maxillofacial, cervical, and thoracic injuries and deterioration of mental status due to a car/pedestrian accident was transferred to our

Received: December 12, 2016 Accepted: September 14, 2017 Online: April 12, 2018

Correspondence: Dr. Mehmet Ozgur ERDOGAN. Department of Emergency Medicine, University of Health Sciences Haydarpasa Numune Training and Research Hospital, Istanbul, Turkey.

Phone: +902165423232 e-mail: ozgurtheerdogan@mynet.com

(c) Copyright 2018 by Istanbul Provincial Directorate of Health - Available online at www.northclinist.com 
emergency department (ED) from a district hospital. The patient's Glasgow score was 10 at referral from the district hospital. He had massive nasal bleeding. In the first hospital, it could not be stopped with anterior nasal packing; thus, a 14-French Foley catheter was used to pack the posterior nose. This did not stop the bleeding either; thus, the patient was transferred to our ED for further evaluation.

When initially examined in our ED, the patient's Glasgow score was 10. He was confused and had multiple lacerations of different depths in the face. He also had massive epistaxis and tachypnea. After the initial assessment, routine laboratory tests and maxillofacial, cranial, cervical, and thoracic computed tomographies (CTs) of the patient were obtained. He had frontal bone, anterior cranial base, and bilateral orbital roof fractures along with nasal bone and $\mathrm{C} 4$ and $\mathrm{C} 7$ vertebrae fractures. He had bilateral frontal contusions and right hemothorax. A massive air bubble was detected inside the brain parenchyma, which was the Foley catheter balloon that was meant to stop the nasal bleeding (Figs. 1, 2). The balloon was deflated slowly, and the Foley catheter was removed by a neurosurgeon. The posterior nasopharynx was packed with gauze via the mouth and supported with anterior nasal packing, which successfully stopped the bleeding. Chest-tube drainage was initiated. Three units of erythrocytes and fresh frozen plasma were

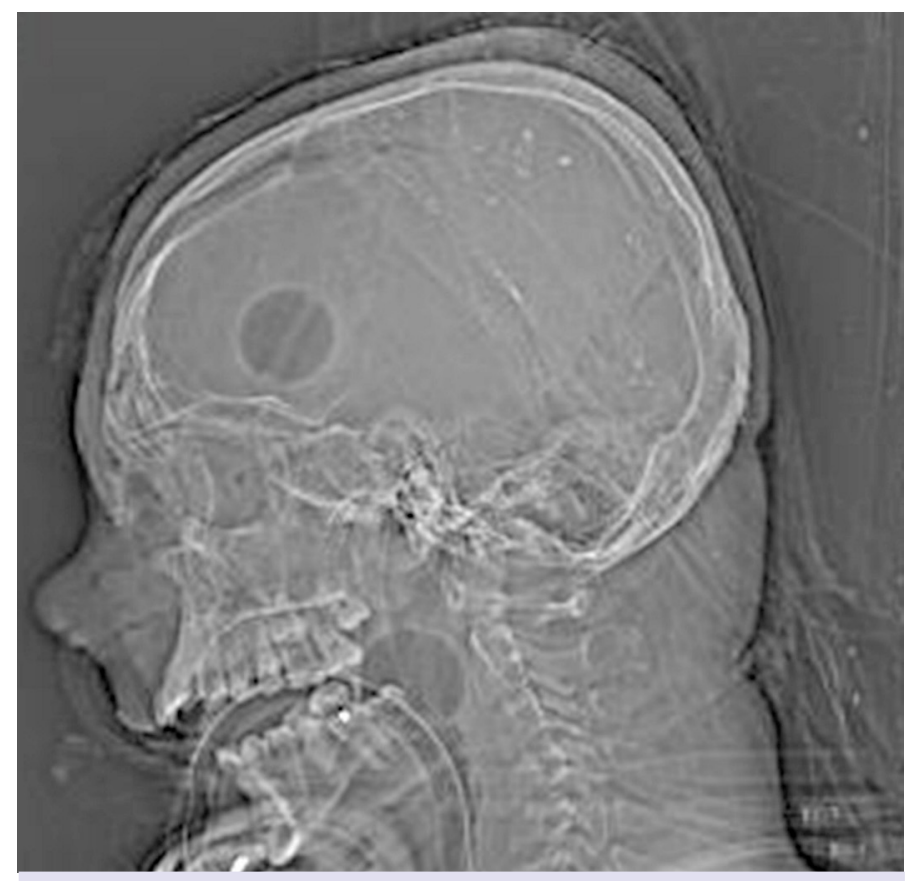

FIGURE 1. Foley catheter in the cranial vault. transfused. After completing emergency interventions, the patient was transferred to the intensive care unit for a close follow-up.

\section{DISCUSSION}

In multiple trauma patients, epistaxis can be a major problem, which might be underestimated or overlooked but can be life threatening. Several arteries from both the internal and external carotid systems supply blood to the nose. The arteries that are usually involved in epistaxis are the internal maxillary, facial, and ophthalmic arteries [1], but any artery could be involved in a patient with maxillofacial trauma. Rupture of any of these arteries can cause life-threatening, massive hemorrhages. Stopping the bleeding can be challenging, as observed in our case, and anterior packing is not always sufficient.

Methods to treat epistaxis vary [2] and range from slight pressure on the nasal ala to arterial embolization or surgical ligation [3]. Posterior nasal packing is another technique, which is less invasive than angiographic or surgical methods but should be applied with great caution, particularly in patients with maxillofacial fractures. Our patient had massive nasal bleeding that could not be stopped by anterior packing, and the otolaryngologist's attempt to stop the bleeding with posterior packing failed because of the defect in the anterior

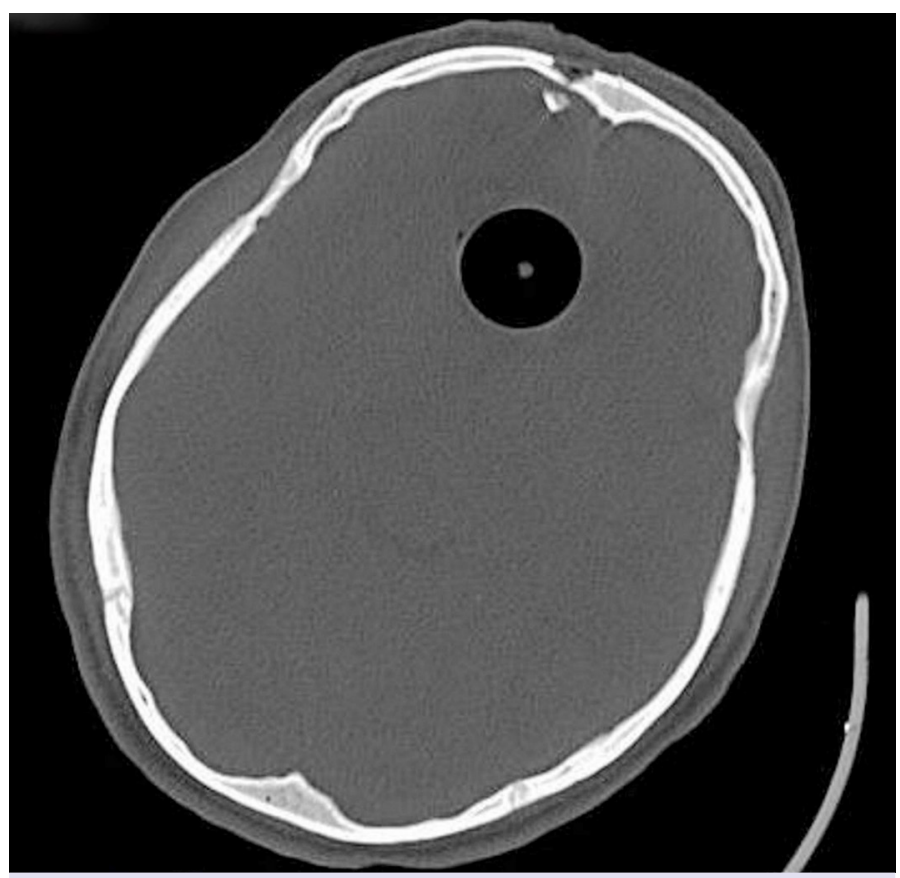

FIGURE2. Foley catheter in the cranial vault. 
skull base. We recommend using nasal endoscopy to place the Foley catheter. A method in which a nasogastric tube is sutured to a flexible bronchoscope and passed into the nasal cavity under direct visualization has been described [4]. The bronchoscope is pulled out of the mouth, the suture is cut, and then the tube is pulled back. This method could be applied to posterior packing with a Foley catheter.

Nasal intubation or nasogastric tube insertion should be avoided in patients with a suspected anterior skull base fracture [1]. Endonasal procedures confer a risk of violating the cranial vault [5].

Despite the fact that Foley catheters are not designed for stopping nasal bleeding, they have been use for this purpose for a long time [6]. Their applicability due to their flexibility is a reason to choose them for posterior packing of the nasal cavity. Although they have been widely used for a long time, only a few cases of intracranial penetration have been reported.

In a literature review about traumatic epistaxis, only 5 of the 33 cases reported to have intracranial penetration of applied instruments were found to be Foley catheters [7]. The rest were nasogastric tubes. The major site for penetration was found to be the cribriform plate. In our case, cribriform plate was also the site of intracranial penetration. This site is more vulnerable to fractures than the other parts of the cranial base because the bony structure of the ethmoid bone is made up of thin lamellar bones. The tiny bony septae can be easily penetrated by application of minor forces.

We report a case in which transnasal posterior packing caused a serious complication due to incomplete evaluation of the trauma patient. Physicians should select and use methods to treat epistaxis very carefully and be alert of unexpected complications at all times. They should not rush into nasal interventions without complete assessment of the stability of the cranial base, no matter how safe the procedure seems or how experienced they are.

Informed Consent: Written informed consent was obtained from the patient who participated in this study.

Conflict of Interest: No conflict of interest was declared by the authors.

Financial Disclosure: The authors declared that this study has received no financial support.

Authorship contributions: Concept - M.O.E., E.O.; Design M.A.A., S.C., I.T.; Supervision - B.E., A.A.; Materials - B.E.; Data collection \&/or processing - M.O.E., E.O.; Analysis and/or interpretation - M.O.E., B.E.; Writing - M.O.E., B.E.; Critical review - M.A.A., I.T., A.A., E.O.

\section{REFERENCES}

1. Krajina A, Chrobok V. Radiological diagnosis and management of epistaxis. Cardiovasc Intervent Radiol 2014;37:26-36. [CrossRef]

2. Villwock JA, Jones K. Recent trends in epistaxis management in the United States: 2008-2010. JAMA Otolaryngol Head Neck Surg 2013;139:1279-84. [CrossRef]

3. Dubel GJ, Ahn SH, Soares GM. Transcatheter embolization in the management of epistaxis. Semin Intervent Radiol 2013;30:249-62.

4. Jones AP, Diddee R, Bonner S. Insertion of a nasogastric tube under direct vision. Anaesthesia 2006;61:305. [CrossRef]

5. Spurrier EJ, Johnston AM. Use of nasogastric tubes in trauma patients-a review. J R Army Med Corps 2008;154:10-3. [CrossRef]

6. Pawar SJ, Sharma RR, Lad SD. Intracranial migration of Foley catheteran unusual complication. J Clin Neurosci 2003;10:248-9. [CrossRef]

7. Veeravagu A, Joseph R, Jiang B, Lober RM, Ludwig C, Torres R, et al. Traumatic epistaxis: Skull base defects, intracranial complications and neurosurgical considerations. Int J Surg Case Rep 2013;4:656-61. 